Lepr Rev (1995) 66, 193-200.

\title{
Editorial
}

\author{
DEFORMITIES AND DISABILITIES- \\ UNFINISHED AGENDA IN LEPROSY WORK
}

\section{Leprosy problems}

From time immemorial leprosy has presented 3 different kinds of problems to mankind. Because there were no effective remedies, it was seen as an incurable disease and so as a medical problem; and as it was seen as a disease capable of spreading from person to person, it was also seen as a health hazard to normal people, i.e. as a public health problem. The disease was also seen as causing bodily impairments, leading to hideous deformities of the face and crippling disabilities involving sight, tactile sensibility, manual dexterity, mobility and even speech. This feature, coupled with incurability and infectiousness, made the community view the disease and the affected persons with abhorrence, as objects to be feared, hated and excluded, and the affected persons similarly perceived themselves. Thus, they lost their status as human beings in their own eyes and in the eyes of their fellow men; and suffered enormously as a consequence. This was the third 'human problem' presented by leprosy.

We must not forget that it was this human problem that moved the hearts and minds of compassionate people all over the world to take up and sustain 'leprosy work' long before any effective remedy was available against the disease; and spurred them to launch and intensify leprosy control and elimination programmes, through governments and voluntary organizations all over the world, as soon as effective remedies against the disease became available. It is particularly important that we remind ourselves of this historical fact.

The advent of dapsone as an effective antileprosy drug signalled the end of leprosy as a medical problem. With the introduction of multidrug therapy (MDT), with rifampicin as an essential component, the medical problem of leprosy has been virtually solved. Leprosy is now an eminently curable disease and future developments can be expected to improve further the situation and provide newer drug regimens to cure the disease even more quickly than now.

Thanks to the above developments, and the concerted efforts of national governments, national and international funding agencies and voluntary organizations, mainly through the sustained endeavours of the World Health Organization (WHO), there has been an enormous mobilization of resources towards making MDT available to all leprosy-affected persons worldwide. The successes achieved so far by way of acceptability of the MDT regimens, reduction in the prevalence of the disease and the very low 
rates of relapses show that we now have an effective and robust technology to meet the challenge of leprosy as a public health problem. ${ }^{1}$ Provided that leprosy work continues with the same input and enthusiasm as at present, we may expect leprosy to become rare even in areas where it was rampant only a few years ago. ${ }^{2}$ We may expect, therefore, that in the very near future leprosy will cease to be a major public health problem.

These spectacular successes in solving the medical and public health aspects of leprosy seem to have created a general impression that the 'leprosy problem' has been virtually solved. The unfortunate choice of the word 'elimination' to indicate the goal of tackling leprosy as a public health problem has helped to strengthen this impression, despite cautionary statements to the contrary, from the WHO as well as others. ${ }^{3-6}$ Some leprosy organizations, both voluntary and governmental, have even started (or are seriously planning) to diversify in to other fields, such as tuberculosis or AIDS.

This is a very disquieting scenario because, by vigorously implementing the current MDT programmes we would have carried out only the minimal necessary and relatively easier task of curing all leprosy-affected persons with MDT. The 'human problem' of leprosy, which has been the motive force of all leprosy work, has hardly been touched on a large scale. Leprosy-related problems such as deformities and disabilities, loom large as the major contributors to the human problem. ${ }^{7}$ Now is the best time for tackling the problem of leprosy-related impairments. The opportunity should not be missed as it will not come again-more on this later.

It is not that we lack knowledge or skills in this area. In fact, ever since leprosy became curable with dapsone, about half a century ago, a number of persons, mainly surgeons and allied paramedical professionals in some institutions, have been gathering experience, developing expertise, carrying out research, collecting information and working out solutions for these problems. In this way reliable knowledge and experience in this field has been accumulated. Nevertheless, despite all our efforts over all these years, we have managed to intervene and improve the life of only a very tiny proportion of affected persons with leprosy-related problems. It is evident that something is not right and the need now is to re-examine the situation, look at the problems afresh and determine our goals, aims and strategies accordingly. This has to be done taking current realities into consideration, since much of our ideas and attitudes are based on experiences now rendered obsolete by the recent and large scale implementation of MDT all over the world.

\section{Current realities}

First, in places where MDT projects have been implemented efficiently for 5-7 years, more than $95 \%$ of persons with leprosy-related impairments are outside the orbit of activities of the leprosy programmes. It is very likely that such persons are far more numerous than those currently taking treatment for leprosy. A proportion of them may be nominally within the programme as 'cases under surveillance' for the present, but the rest of them are completely outside the programme as 'released from control'.

Second, surveillance is not carried out with the same efficiency and enthusiasm as treatment (MDT) activities. Even when conducted diligently, surveillance involves seeing recently treated leprosy-affected persons once a year, for a few minutes, for 2-5 years. It has recently been proposed that even this meagre surveillance programme should be dispensed with, because relapses after MDT (the main reason for surveillance) are too few. ${ }^{1,8,9}$ 
Third, as MDT projects progress, more and more persons suffering from leprosyrelated impairments will be returned to the community as 'disease cured', which means more and more such persons will be beyond the reach of the safety net of leprosy programmes.

Fourth, the existing specialist leprosy institutions with the needed expertise in deformity management etc., are hopelessly inadequate in numbers to meet the situation, and we cannot expect persons with leprosy-related impairments to travel long distances to strange places for each different problem every so often.

Fifth, the main problem is not persons developing impairments for the first time. As with leprosy control, the main problem is the backlog of prevalent cases, namely those who have already developed some impairment such as loss of sensibility or muscle paralysis. Many workers, including physicians, continue to think that we can significantly reduce the quantum of leprosy-related impairments if only it was possible to monitor patients more carefully during treatment, recognize impairment-inducing conditions such as reactions and neuritis very early, and initiate 'proper' treatment. This idea is based on our past experiences, especially in institutions, during the dapsone days. It has become obsolete now because leprosy patients are under treatment for such a short period (and we may expect the treatment period to become even shorter still in the near future) and only a tiny proportion of those taking treatment will develop impairments for the first time while under treatment, or afterwards, and thus get added to the existing pool of such persons. ${ }^{10,11}$ The primary problem, therefore, is persons who already have leprosy-related impairments becoming worse and not that of leprosy-affected patients developing impairments for the first time.

Sixth, unless special measures, referred to as 'Disability Prevention Practices', are taken and continued indefinitely, persons having leprosy-related impairments will inevitably worsen in their impairment-disability status irrespective of whether their deformities are corrected or not, or whether they have been rehabilitated or not. Sooner or later, the insensitive and dry parts (eyes, hands, feet) will develop wounds and ulcers and the joints affected by muscle paralysis will develop progressively increasing stiffness.

Seventh, leprosy workers, however motivated, knowledgeable and compassionate they may be, can provide only periodic, occasional or one-off interventions to help affected persons, whereas 'disability prevention' requires conscious and continuous care for the rest of their lives.

Finally, as already stated, we in the leprosy sector have sufficient knowledge and skills to prevent any worsening of the impairment-disability status of leprosy-affected persons.

\section{New goals and aims}

It should be evident from the above that leprosy workers cannot prevent the worsening of most leprosy cases with impairment disabilities, although it is known how to achieve this, and that the outcome rests with the efforts of the affected persons themselves. In short, leprosy workers have the solution but the affected persons have the problem. This in essence has been and continues to be the core of the problem. When viewed in this manner, it becomes obvious that, instead of concentrating our efforts on preventing impairments in affected persons, we should direct our activities at empowering affected persons to prevent 
the worsening of their impairment status by their own initiatives and efforts. It appears that we can achieve our goal of preventing worsening of the impairment-disability status of leprosy-affected persons only through the strategy of empowering them and supporting them in this regard. Achieving this will be more difficult than putting pills and capsules into the mouths of patients and making them swallow. These difficulties arise because in a programme of this sort we are attempting to change people's attitudes and behaviour for intangible, long term, negative benefits ('no worsening of impairments and disabilities'). The difficulties are further increased because in carrying out a programme of this kind, namely empowering people, leprosy workers will have to learn to play a role quite different from their traditionally recognized and appreciated role as providers of certain goods and services in the health sector. Thus, this programme also aims at changing our own attitudes and behaviour for intangible, long term and uncertain (uncertain because we are dealing with human beings) benefits ('the affected persons become skilled in disability prevention and use those skills in their daily lives').

\section{Empowerment and its requirements}

The term 'empowerment' is commonly used in the political-sociological context to refer to a state of socially sanctioned authority and power to act. It thus indicates a state of self-reliance and nondependence on external agencies for exercising that power. It also implies the availability of supportive services to provide assistance in areas beyond the reach of the local community, and easy access to them, in order to make empowerment meaningful. While in legal parlance individuals are usually empowered to do something, in political-sociological parlance it is communities or classes of people, previously powerless, which are sought to be empowered to order their lives according to their needs in certain contexts. 'Empowerment', therefore, involves possession of requisite knowledge, acquisition of needed skills, the freedom to use them and ready access to support facilities.

The 3 key aims of activities in implementing a comprehensive project to empower leprosy-affected persons to prevent the worsening of their impairment-disability status by their own efforts will be: (i) changing attitudes and behaviour; (ii) technology transfers; and (iii) creation and strengthening of certain support facilities. These activities need to be targeted towards 3 different groups: (i) leprosy programme personnel at all levels; (ii) general health care professionals at different levels; and (iii) certain sections of the local community (namely persons suffering from or likely to develop leprosy-related impairments, their family members and local community volunteers and opinion leaders). These activities mutually reinforce each other and so they need to be carried out concurrently and not serially. However, because of practical constraints, we may start with the activity that is most feasible in the given situation in order to pave the way for taking up the other 2 at the earliest convenience.

The core objectives of the 3 activities listed above vis-à-vis the 3 target groups also listed above are briefly outlined below.

CHANGING ATTITUDES AND BEHAVIOUR

As mentioned earlier, leprosy programme personnel at all levels should thoroughly 
understand the need for the empowerment of affected persons and the community, its requirements, and change the concepts of their roles and actions accordingly, from being providers of certain goods and services to becoming facilitators, trainers and catalytic agents to bring about the required outcome, which is to make affected persons and local community self-reliant and take responsibility in the matter of 'disability prevention'.

General health care professionals should also understand what leprosy workers are trying to achieve, and change their attitude towards their obligations to leprosy-affected persons from neglect and indifference to acceptance and willingness to shoulder their responsibility in the programme.

The targeted public and local community are expected to change their customary attitude of fatalistic acceptance of their lot and helpless dependence on the leprosy programme, and others, to an attitude of informed self-reliance and non-dependence, and start acting accordingly.

\section{TRANSFER OF TECHNOLOGY}

A successful disability management programme that empowers the community depends on a variety of technology transfers and training programmes of different complexity to effect those transfers. By 'technology transfer' I am referring to a shift in the possession of relevant knowledge and skills from one party to another through appropriate training programmes in a planned manner.

There are 3 kinds of technology transfers involving the 3 parties required here:

(i) The leprosy programme staff at all levels need to develop the skills for motivating and activating affected persons and other target groups in the community. This will require technology transfer from social scientists and community workers like community-based rehabilitation (CBR) personnel and social workers, to the leprosy programme personnel through appropriate training programmes.

(ii) General health care professionals at 2 different levels will need to develop knowledge and skills from the leprosy programme:

(a) at field or peripheral level-to replace or assist leprosy programme personnel on a continuing basis (for the identification and training of target persons and groups as well as to treat locally treatable conditions); and (b) at regional or district level-physicians and specialists should be trained to provide higher level medical care, particularly in the management of deformities, neuritis and reactions and in the treatment of complicated foot and eye problems as well as for the provision of orthotic and prosthetic devices and other appliances.

(iii) The 3rd and the most crucial technology transfer involves target persons and groups in the community (affected persons, their family members and community volunteers). The required knowledge and skills for 'disability prevention' now residing with the leprosy sector need to be transferred to the target groups so that they become knowledgeable about leprosy-related impairments, become skilled in their recognition, management and prevention and become motivated to practise those skills in their daily lives. This is the most important activity and all the other activities are for re-inforcing this and are, in fact, aimed at making this succeed. If this fails, the entire purpose of the 'disability prevention' programme is lost. 


\section{SUPPORT SERVICES}

There will be many problems which cannot be tackled by the affected persons at the peripheral level using simple measures. In order to meet them successfully supportive services will be required, without which all talk about 'empowerment' will be a meaningless mockery and all efforts towards empowerment will be doomed to become misspent. Therefore, creation and strengthening of appropriate support services and making them easily accessible to affected persons is an essential component of the empowerment strategy.

In the present context of our discussion, support services are needed to serve 3 different purposes: (i) providing aids and appliances, namely protective footwear, splints (for fingers mainly), orthotic/prosthetic and other appliances like grip aids, etc.; (ii) treating locally treatable conditions, particularly ulcers, at the peripheral (control unit/health centre) level; and at a more central (district or regional level); and (iii) providing higher level medical care for dealing with the complications of leprosy as well as for correction of deformities and improvement of disabilities and treatment of complicated foot problems, including recurrent plantar ulcers. Meeting the above needs requires strengthening the services already available with the leprosy sector and the general health care services.

Besides the above, there is another very important support facility that has to be created - that is having an informed and interested community prepared to intervene in the interests of those with impairments and disabilities, including leprosy-related ones. This can play a very positive role by providing a favourable climate for disability prevention and management as well as for obtaining active help from local resources for various disability-related activities, such as the supply of aids and appliances, community-based rehabilitation and even professional help from local private medical and industrial organizations. Table 1 summarizes the core objectives mentioned above.

\section{Now is the time}

It will be seen from the above that 'leprosy work', contrary to what many people seem to think, is far from 'finished'. The achievement of 'elimination of leprosy as a public health problem' marks only the beginning. After that, we must not be distracted by the medical and public health problems of leprosy, from making the 'final assault' on the millenia old human problem of leprosy. But that does not mean we have to wait till the elimination goal is achieved. In fact, if we do that, it will be too late. Now is the time to start, for a number of reasons. First, the climate is just right at present, with MDT showing great reductions in prevalence, whereas there is the danger that the present positive proactive disposition among governments, workers and donor agencies will disappear by the time we achieve world-wide elimination. Second, experts in this area are, after all, mortal human beings, and by that time, the hard-won expertise developed over the last half a century and available till now will also have become quite scarce, making the initiation of training programmes on a large scale difficult, especially in deformity correction and ulcer management. Third, the work load of leprosy field workers has diminished considerably in MDT project areas and in these persons we have a ready source of manpower familiar with leprosy-affected persons and their problems as well as the local 
Table 1. Core objectives of 'empowerment' activities vis-à-vis target groups

\begin{tabular}{|c|c|c|c|}
\hline \multirow[b]{2}{*}{$\begin{array}{l}\text { Empowerment } \\
\text { activity }\end{array}$} & \multicolumn{3}{|c|}{ Target groups } \\
\hline & $\begin{array}{l}\text { Leprosy programme } \\
\text { personnel }\end{array}$ & $\begin{array}{c}\text { General health care } \\
\text { professionals }\end{array}$ & Local community* \\
\hline $\begin{array}{l}1 \text { Change attitude } \\
\text { and behaviour }\end{array}$ & $\begin{array}{l}\text { From being providers } \\
\text { of goods and services } \\
\text { to becoming facilitators } \\
\text { and trainers }\end{array}$ & $\begin{array}{l}\text { From an attitude of } \\
\text { neglect of leprosy-affected } \\
\text { patients to accepting and } \\
\text { caring for them }\end{array}$ & $\begin{array}{l}\text { From being dependent } \\
\text { on leprosy services to } \\
\text { becoming self-reliant }\end{array}$ \\
\hline $\begin{array}{l}2 \text { Transfer } \\
\text { technology }\end{array}$ & $\begin{array}{l}\text { Learn from social } \\
\text { scientists and community } \\
\text { workers to function as } \\
\text { facilitators, trainers and } \\
\text { catalytic agents of change }\end{array}$ & $\begin{array}{l}\text { Learn disability } \\
\text { management and deformity } \\
\text { correction from the leprosy } \\
\text { sector }\end{array}$ & $\begin{array}{l}\text { Learn to manage } \\
\text { leprosy-related } \\
\text { impairments } \\
\text { themselves }\end{array}$ \\
\hline $\begin{array}{l}3 \text { Provide support } \\
\text { facilities }\end{array}$ & $\begin{array}{l}\text { (a) Treat locally treatable } \\
\text { conditions especially } \\
\text { plantar ulcers; } \\
\text { (b) help to acquire aids and } \\
\text { appliances; and } \\
\text { (c) arrange ref erral facilities } \\
\text { for higher level medical } \\
\text { care }\end{array}$ & $\begin{array}{l}\text { (a) Treat locally treatable } \\
\text { conditions; } \\
\text { (b) provide higher level } \\
\text { medical care; and } \\
\text { (c) arrange and supply } \\
\text { aids and appliances }\end{array}$ & $\begin{array}{l}\text { Build community } \\
\text { support for CBR, } \\
\text { supply of aids and } \\
\text { appliances and services } \\
\text { from private medical } \\
\text { sector and others }\end{array}$ \\
\hline
\end{tabular}

*Local community here refers to: persons with leprosy-related impairments, disabilities and handicaps, their family members, local community volunteers and opinion leaders.

communities, for our use. Such an asset will not be available later and it should not be frittered away now in other areas just because leprosy has been 'eliminated' as a public health problem. Fourth, many among the field workers are still not quite satisfied with their achievements, despite the success of MDT, because they find that the miserable lot of persons with leprosy-related impairments, deformities and disabilities has not changed in any way. Motivating them now in 'Disability Prevention' will not be difficult. Lastly, viewing this exercise from a broader perspective, the experience gained in implementing empowerment projects in leprosy will prove very valuable for use in other health-related and community-based rehabilitation work for which a base will have been created where no such base exists now.

\author{
'Beach Residency' \\ 12/1, First Seaward Road \\ Valmiki Nagar \\ Madras-600 041 \\ India
}

H. SRINIVASAN

\title{
References
}

1 Daumerie D, Pannikar V. Issues i n evaluating information on relapse in leprosy. Indian J Lepr, 1995; 67: $27-33$.

2 Noordeen SK. Elimination of leprosy as a public health problem. Indian J Lepr, 1994; 66: 1-10.

3 Noordeen SK. Elimination of leprosy as a public health problem. Indian J Lepr, 1991; 63: 401-9.

${ }^{4}$ Srinivasan H. Newer tasks for leprosy workers, Indian J Lepr, 1990; 62: 409-15. 
5 Elimination of Le prosy: Questions and Answers. Leprosy Control Programme, World Health Organization, Geneva, 1993.

6 Srinivasan H. Not by chemotherapy alone. Indian J Le pr, 1994; 66: 209-21.

7 Srinivasan H. To control leprosy - as if the patient mattered. Indian J Le pr, 1984; 56: 386-95.

8 Chemotherapy of leprosy, Report of a WHO study group, WHO Tech Rep Ser, 847, 1994.

9 Risk of relapse in leprosy. WHO/CTD/LEP/94.1. Paper prepared by The Leprosy Unit, WHO. Indian $J$ Le pr, 1995; 67: 13-26.

10 Pönnighaus IM, Boerrigter G, Fine PEM, Pönnighaus JM, Russell J. Disabilities in leprosy patients ascertained in a total population survey in Karonga District, Northern Malawii. Le pr Rev, 1990; 61: 366-74.

11 Rao PS, Subramanian M, Subramanian G. Deformity incidence in leprosy patients treated with multidrug therapy. Indian J Lepr, 1994; 66: 449-54. 